\title{
In situ direct photoproduction of ketenes from substituted coumarins isolated in solid argon: The case of $\mathrm{N}$-(2-oxo-2H-chromen-3-yl)acetamide
}

\author{
N. Kuş ${ }^{a, b, *}$, S. Breda ${ }^{a}$, R. Fausto ${ }^{a}$ \\ ${ }^{a}$ Department of Chemistry, University of Coimbra, P-3004-535 Coimbra, Portugal \\ ${ }^{\mathrm{b}}$ Department of Physics, Anadolu University, 26440 Eskişehir, Turkey
}

\section{A R T I C L E I N F O}

\section{Article history:}

Received 25 July 2008

Accepted 6 October 2008

Available online 21 October 2008

Keywords:

Matrix isolation

Infrared spectroscopy

DFT calculations

UV-induced photochemistry

3-Acetamidocoumarin

\begin{abstract}
A B S T R A C T
In this study, the infrared spectrum of $\mathrm{N}$-(2-oxo-2H-chromen-3-yl)acetamide (3-acetamidocoumarin; $3 \mathrm{AC}$ ) isolated in solid argon, at $10 \mathrm{~K}$, was obtained and assigned. In consonance with the relative energies of the three conformers predicted theoretically, only the most stable form was observed experimentally. This conformer is stabilized by two intramolecular hydrogen bonds and is similar to the structural unit of $3 \mathrm{AC}$ found in crystalline phase. Upon in situ $\mathrm{UV}(\lambda>215 \mathrm{~nm})$ irradiation of the matrix-isolated compound, the characteristic IR intense band due to the antisymmetric stretching vibration of the ketene $(-C=C=0)$ group was observed, indicating occurrence of the ring-opening isomerization reaction to the open-ring ketene isomeric of $3 \mathrm{AC}$. In consonance with the theoretical structural predictions for the most stable isomers of this photoproduct, the experimental data indicates that it is produced in the $\mathrm{E}$ arrangement of the $(\mathrm{O}=) \mathrm{C}-\mathrm{C}=\mathrm{C}-\mathrm{C}(=\mathrm{C}=\mathrm{O})$ fragment. There were also experimental indications pointing to occurrence of a second photoreaction channel, corresponding to decarbonylation. On the other hand, contrarily to what is generally observed for $\alpha$-pyrones derivatives, including unsubstituted coumarin, no photochemical production of Dewar isomer of 3AC was observed. This last result, follows the trend observed for 2-pyrone-3-carboxylate, and seems to be a quite general rule for matrix-isolated $\alpha$-pyrones bearing relatively volumous substituents at the position 3 , as a consequence of the unfavorable relaxation of the matrix around the guest molecule that would be required to accommodate the Dewar isomers of these compounds, whose structure deviates strongly from planarity, thus mismatching the primarily occupied matrix sites.
\end{abstract}

(c) 2008 Elsevier B.V. All rights reserved.

\section{Introduction}

Coumarins are important natural occurring and synthetic compounds which show several relevant applications. In particular, they exhibit different biological activities, including anticoagulant, spasmolytic, diuretic, anthelmintic and hypoglucemic actions [1-8].

The properties of coumarins are in large extent determined by their constituting $\alpha$-pyrone unit, which has been shown to present a very rich photochemistry [9-14]. In general, $\alpha$-pyrones undergo two main competitive photochemical reactions: ring-opening, leading to formation of the isomeric open-ring ketenes, and ring-contraction to the corresponding Dewar isomers [9-14]. However, the precise photochemistry and relative importance of these two photochannels is strongly dependent on the substituents present in the heterocyclic ring. For example, it has been demonstrated that

\footnotetext{
* Corresponding author. Address: Department of Chemistry, University of Coimbra, P-3004-535 Coimbra, Portugal.

E-mail address: nkus@anadolu.edu.tr (N. Kuş).
}

the Dewar isomer formation is much more effective for most of the substituted derivatives, while the ring-opening photoreaction, leading to the isomeric ketene, proceeds easier for unsubstituted $\alpha$-pyrone. The ring-opening reaction leading to the ketene species is believed $[15,16]$ to originate from excited states with $n \pi^{*}$ character, whereas the process leading to formation of the Dewar isomers should start from $\pi \pi^{*}$ states. In $\alpha$-pyrones, the lowest excited singlet state has $n \pi^{*}$ character [17]. Hence, the $n \pi^{*}$-type photochemistry is favored for these compounds when they are free of any substituents. On the other hand, conjugative type substitution with groups such as $-\mathrm{OH},-\mathrm{CH}_{3}$ or $-\mathrm{OCH}_{3}$, blue-shifts the $\mathrm{S}_{1} \leftarrow \mathrm{S}_{0}\left(\mathrm{n} \pi^{*}\right)$ transition and red-shifts the $S_{2} \leftarrow S_{0}\left(\pi \pi^{*}\right)$ transition [17,18], reducing the gap between the $S_{1}$ and $S_{2}$ states and favoring the process leading to the Dewar formation. Note that the ring-opening reaction in $S_{1}$ is not a barrierless process $[19,20]$ and some excess of excitation energy is needed to promote the $\alpha$-bond cleavage. Hence, this process does not necessarily need to dominate, even though the lowest of the excited states is of $n \pi^{*}$ character. If the energy gap between the $\mathrm{n} \pi^{*}$ and $\pi \pi^{*}$ states is not too large, the processes typical 
for $\pi \pi^{*}$ photochemistry can compete with the $\alpha$-bond cleavage or even dominate. Isomerizations to the Dewar forms observed as dominating processes for 4,6-dimethyl- $\alpha$-pyrone, 4-hydroxy- and 4 -methoxy-6-methyl- $\alpha$-pyrones are good examples of such behavior $[9,10]$.

Very interestingly, for the matrix-isolated compounds, when the substituent is a volumous group at the position 3 of the $\alpha$-pyrone ring, the ring-contraction reaction becomes less easy and, at least in some cases, it does not occur at all. This has been recently observed for matrix-isolated 3-methyl coumalate, where only the ring-opening reaction was observed $[13,14]$. On the other hand, the 5-substituted analogue (5-methyl coumalate) shows the expected dominance of the Dewar isomerization process over the ring-opening reaction, as found for the other substituted $\alpha$-pyrones already studied.

Recently, we have described the photochemistry of matrix-isolated coumarin [21]. This compound was shown to react according to three main reaction channels, two of them corresponding to those previously observed for matrix-isolated $\alpha$-pyrones: (a) decarboxylation to form bicyclo[4.2.0]octa-1,3,5,7-tetraene and $\mathrm{CO}_{2}$, with the Dewar form of coumarin as intermediate; (b) isomerization leading to the conjugated ketene isomer. The third observed reaction pathway, decarbonylation, with production of a $\mathrm{CO} /$ benzofuran complex, follows the dominant UV-induced photochemistry of coumarin in gas phase [22].

In the present study, we focused our attention on $\mathrm{N}$-(2-oxo- $2 \mathrm{H}$ chromen-3-yl)acetamide (3-acetamidocoumarin; 3AC. Scheme 1), which is a substituted coumarin bearing a relatively volumous substituent at the position 3 of the $\alpha$-pyrone ring. As it will be shown, for this compound isolated in a cryogenic inert matrix the photochemical channel leading to formation of the Dewar isomer is also closed.

\section{Materials and methods}

\subsection{Experimental details}

$\mathrm{N}$-(2-oxo-2H-chromen-3-yl)acetamide (3-acetamidocoumarin; $3 A C)$ was purchased from Sigma (purity 99\%) and used without any further purification. The infrared spectra were obtained using a Mattson (Infinity 60AR Series) Fourier transform infrared spectrometer, equipped with a deuterated triglycine sulphate (DTGS) detector and a $\mathrm{KBr}$ beamsplitter, with $0.5 \mathrm{~cm}^{-1}$ spectral resolution. Necessary modifications of the sample compartment of the spectrometer were done in order to accommodate the cryostat head and allow purging of the instrument by a stream of dry nitrogen to remove water vapors and $\mathrm{CO}_{2}$. A solid sample of $3 \mathrm{AC}$ was placed in a specially designed mini-oven assembled within the cryostat and sublimated by heating the compound to $125^{\circ} \mathrm{C}$. The vapor of $3 \mathrm{AC}$ was then codeposited together with large excess of the host matrix gas (argon N60, from Air Liquide) onto a cold CsI window

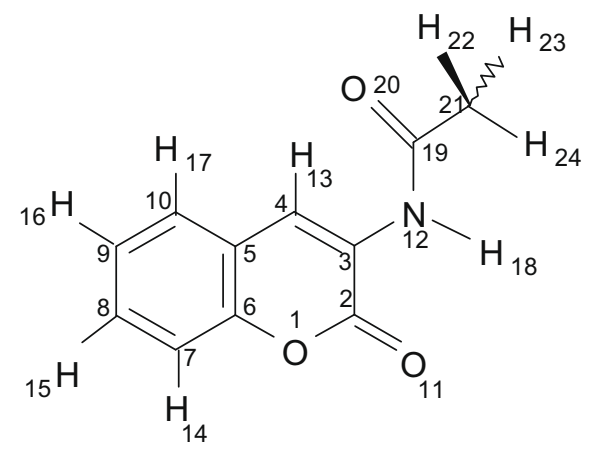

Scheme 1. $3 A C$ with atom numbering scheme adopted in this study.
( $T=10 \mathrm{~K})$ mounted on the tip of the cryostat. All experiments were done on the basis of an APD Cryogenics close-cycle helium refrigeration system with a DE-202A expander. The matrices were irradiated through the outer quartz window of the cryostat, using a $200 \mathrm{~W}$ output power of a $500 \mathrm{~W} \mathrm{Hg}(\mathrm{Xe})$ lamp (Oriel, Newport). Different cut-off filters were used: $\lambda>337,315,285,235 \mathrm{~nm}$ and, finally, unfiltered radiation $(\lambda>215 \mathrm{~nm})$.

\subsection{Computational methodology}

The equilibrium geometries for $3 \mathrm{AC}$ and its photoproducts were fully optimized at the DFT level of theory with the $6-311++G(d, p)$ split valence triple- $\zeta$ basis set. The DFT calculations were carried out with the three-parameter B3LYP density functional, which includes Becke's gradient exchange correction [23] and the Lee, Yang, Parr correlation functional [24]. All calculations were carried out using the Gaussian 03 program package [25].

Vibrational spectra were calculated at the same level of theory. Transformations of the Cartesian force constants to molecule-fixed symmetry adjusted internal coordinates allowed the ordinary normal coordinate analysis to be performed as described by Schachtschneider [26]. The symmetry internal coordinates used in this analysis were defined as recommended by Pulay et al. [27] and are provided as Supplementary data (Table S1). Potential energy distribution (PED) matrices [28] have been calculated and the elements of these matrices greater than $10 \%$ were used to characterize the different vibrations in terms of the chosen symmetry coordinates.

\section{Results and discussion}

\subsection{Geometries and energies}

Isolated molecule of $3 \mathrm{AC}$ has never been studied previously either experimentally or theoretically. To the best of our knowledge, only two reports appeared previously on this compound. The first one is a ${ }^{1} \mathrm{H}$ and ${ }^{13} \mathrm{C}$ NMR study, which provides chemical shifts for $3 \mathrm{AC}$ in DMSO- $d_{6}$ solution at room temperature, and suggests that the compound should exist under those experimental conditions predominantly in a conformation where the two carbonyl groups are anti to each other [29]. The second study [30] considered the room temperature crystalline phase of the compound. The crystals were found to be monoclinic ( $a=10.0907$, $b=4.8785, c=19.096 \AA$ ), space group $P 2(1) / c$, with 4 molecules per unit cell. In the crystal, the molecules exhibit a conformation where the two carbonyl groups are anti to each other and are interacting by strong intermolecular $\mathrm{N}-\mathrm{H}$. . $\mathrm{O}=\mathrm{C}$ (ring) hydrogen bonds forming anti-parallel dimers. The dimers are aligned forming twincolumns through weak $\pi$-stacking interactions and weaker C-H. . .O (ring) hydrogen bonds [30]. The common element to these previous studies is the found preference for the molecule of $3 \mathrm{AC}$ to assume a conformation where the two carbonyl groups are anti to each other.

In the present study, we performed a detailed conformational search on the B3LYP/6-311++G(d,p) potential energy surface of the $3 \mathrm{AC}$ molecule. From this search, three different conformers could be identified. These conformers are depicted in Fig. 1. Selected geometrical parameters for these forms are provided as Supplementary data (Table S2) where they are compared with those obtained by X-ray [29] and also with those calculated at the same level of theory for the parent compound, coumarin [21].

According to the calculations, the most stable conformer of $3 \mathrm{AC}$ corresponds to the structure observed in the crystalline state [29]. For the isolated molecule, two intramolecular hydrogen bonds characterize this conformer, the first established between the NH group and the $\alpha$-pyrone ring carbonyl oxygen atom (with the $\mathrm{NH}$. . .O dis- 


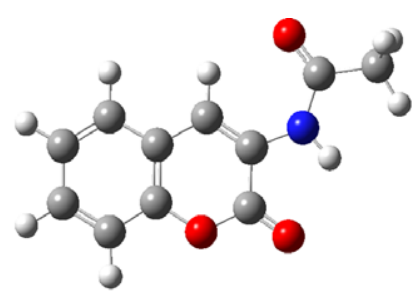

I

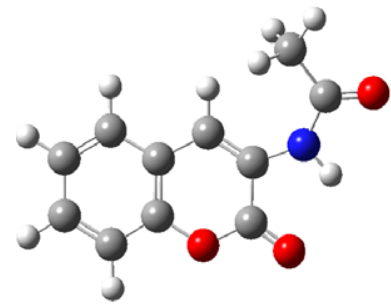

II

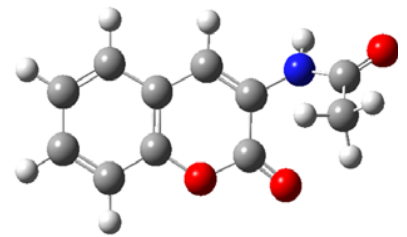

III
Fig. 1. Conformers of $3 A C$ and their relative energies (with zero-point vibrational corrections), as calculated at the DFT(B3LYP)/6-311++G(d,p) level of theory.

tance and $\angle \mathrm{N}-\mathrm{H}$. . .O angle equal to $2.186 \AA$ and $107.8^{\circ}$, respectively), and the second between the $\mathrm{C} 4-\mathrm{H}$ and the amide oxygen (C4H...O, $\left.2.242 \AA ; \angle \mathrm{C} 4-\mathrm{H} . .0,116.8^{\circ}\right)$. These two intramolecular hydrogen bonds strongly stabilize this conformer, which is predicted to be more stable than the conformers II and III by 27.4 and $37.9 \mathrm{~kJ} \mathrm{~mol}^{-1}$, respectively (zero-point energy corrected energy differences). In conformer II, the $\mathrm{NH}$...O hydrogen bond is kept (NH...O, $2.167 \AA ; \angle \mathrm{N}-\mathrm{H} . . .0,108.1^{\circ}$ ), but the second H-bond interaction is replaced by a repulsive interaction between the methyl group and the hydrogen atom bound to C4 (see Fig. 1), whereas in conformer III no intramolecular hydrogen bonds are present.

The presence of the two H-bonds in conformer I is clearly revealed by the relative values of the $\mathrm{C}=0$ bond lengths calculated for the different conformers ( $C 2=0: 1.210 \AA$ in I and $1.207 \AA$ in II, where the hydrogen bond are present, and $1.201 \AA$ in form III, where it does not exist; $C 19=0: 1.219 \AA$ in I, vs. $1.216 \AA$ in both II and III). It is also interesting to note that the presence of the $\mathrm{NH}$. . O bond in conformers I and II of $3 \mathrm{AC}$ makes the $\mathrm{O} 1-\mathrm{C} 2$ bond ( $\alpha$ to the carbonyl) becoming much shorter than in unsubstituted coumarin ( $1.365 \AA$ vs. $1.396 \AA$; in conformer III, this bond is $1.386 \AA$, much closer to the value found in coumarin; Table S2), since it leads to a more electronegative carbonyl carbon atom, which then favors the electron delocalization from the 01 lone electron pairs to the $\mathrm{O} 1-\mathrm{C} 2$ bond, increasing its double bond character. On the other hand, as it could be expected, the $01-\mathrm{C} 6$ bond length varies in the opposite direction, attaining its maximum value in $3 A C$ form I $(1.374 \AA$ ) and minimum value in coumarin (1.365 A) (see Table S2).

The calculations predicted all the conformers to belong to the $C_{1}$ point group, though the deviation of form I from $C_{\mathrm{s}}$ symmetry is very small, corresponding only to a slight skewing ( $\left.\mathrm{ca} .4^{\circ}\right)$ of the methyl group from the alignment with the molecular plane (Table S2). A similar small geometric distortion in the $\mathrm{CH}_{3}-\mathrm{C}(=\mathrm{O})$ moiety from the symmetric $C_{s}$ geometry was recently reported for hydroxyacetone [31]. As found for hydroxyacetone [31], the energy difference between the $C_{s}$ structure and the two symmetrically equivalent minima it separates stays below the zero-point vibrational level of these later, which means that in practical terms the relevant (most probable) structure is the symmetric one. In conformers II and III, the planes of the coumarin and acetamide fragments make angles $(\mathrm{C} 4=\mathrm{C} 3-\mathrm{N} 12-\mathrm{C} 19)$ of $14.5^{\circ}$ and $128.2^{\circ}$, respectively. In conformer II, the deviation of the two fragments from being in the same plane is essentially determined by the repulsion between the methyl group and the hydrogen atom bound to C4, while in form III it results mainly from the sterically more relevant interaction between the methyl group and the $\alpha$ pyrone ring carbonyl group (see Fig. 1).

\subsection{Infrared spectrum of the as-deposited matrix}

Taking into consideration the predicted relative energies of the 3 conformers of $3 \mathrm{AC}$, it can be easily estimated that conformer I accounts for more than $99 \%$ of the total population in gas phase at $125^{\circ} \mathrm{C}$, the temperature of sublimation of the compound used to prepare the matrices. Hence, this form can be expected to be the sole form present in the as-deposited matrix. Fig. 2 shows the infrared spectrum of the as-deposited $3 A C$ in argon matrix, at $10 \mathrm{~K}$, and the B3LYP/6-311++G(d,p) predicted spectrum for conformer I. The full set of calculated frequencies and infrared intensities and normal coordinate analysis results for the 3 conformers of 3AC are provided in the Supplementary data (Tables S3-S5). As it can be seen in Fig. 2, the calculated spectrum of conformer I agrees very well with the experimentally observed spectrum. The assignment of the observed spectrum is given in Table 1. The following observations deserve further discussion:

(a) The experimental spectrum reveals existence of multiple trapping sites of the $3 \mathrm{AC}$ molecule in the matrix. This can be observed in all spectral regions, but it is very clearly evidenced, for instance, in the $\mathrm{N}-\mathrm{H}$ and $\mathrm{C}=\mathrm{O}$ stretching regions, around $3400 \mathrm{~cm}^{-1}$ and in the $1750-1700 \mathrm{~cm}^{-1}$ range (Fig. $2 \mathrm{~A}$ and $\mathrm{B}$ ). Multiple matrix trapping sites are commonly observed for heterocyclic compounds $[32,33]$ and they were found to be particularly numerous for molecules containing the $\alpha$-pyrone moiety, including coumarin itself [21]. Explanation for this fact is certainly out of the scope of this study, but appears as an interesting question that might eventually be successfully addressed by using appropriate theoretical approaches (e.g., molecular dynamics).

(b) According to the theoretical data, one can expected to observe two intense bands in the $1375-1355 \mathrm{~cm}^{-1}$ spectral range. The highest frequency band should correspond to the symmetric methyl bending mode and have an intensity less than half of that of the lowest frequency band, which should correspond to a vibration with the largest contribution located in the $\delta(\mathrm{C} 4-\mathrm{H})$ oscillator (see Table 1). On the other hand, the relative intensities of the observed bands in the same spectral range (ca. 1372 and $1358 \mathrm{~cm}^{-1}$ ) appear with the opposite relative intensities (Fig. 2). Similar situations involving vibrations mainly localized in the $\mathrm{C} 4-\mathrm{H}$ bond can also be noticed in the $1205-1160 \mathrm{~cm}^{-1}$ and $925-910 \mathrm{~cm}^{-1}$ spectral ranges (see Table 1 ). As mentioned before, in the experimentally relevant conformer of $3 \mathrm{AC}$ (conformer $\mathrm{I}$ ) the $\mathrm{C} 4-\mathrm{H}$ bond is involved in an intramolecular $\mathrm{H}$-bond. The observed inconsistencies can then be correlated with the expected greater sensitivity of the vibrations associated with the $\mathrm{H}$-bond interacting groups to media effects. The assignments for these bands proposed in Table 1 were based on the relative intensities of the bands.

(c) The predicted position for the $\mathrm{vN}-\mathrm{H}$ stretching band is $c a$. $3500 \mathrm{~cm}^{-1}$ (scaled value). However, the corresponding experimental band is observed at a considerably lower frequency $\left(\sim 3400 \mathrm{~cm}^{-1}\right)$. This is an indication that the calculations underestimate in some extent the strength of the $\mathrm{NH}$...O intramolecular hydrogen bond. Taking this into consideration, one can expect that the frequency of the $\gamma \mathrm{N}-\mathrm{H}$ rocking mode is underestimated by the calculations, since this mode is also well known to be very sensitive to the $\mathrm{H}$-bond strength, increasing its frequency with the strength of the hydrogen bond [34-36]. Indeed, the calculations predict the $\gamma \mathrm{N}-\mathrm{H}$ rocking mode at $670 \mathrm{~cm}^{-1}$, while the band in the experimental spectrum ascribable to this vibration is observed at $778 \mathrm{~cm}^{-1}$. 
A
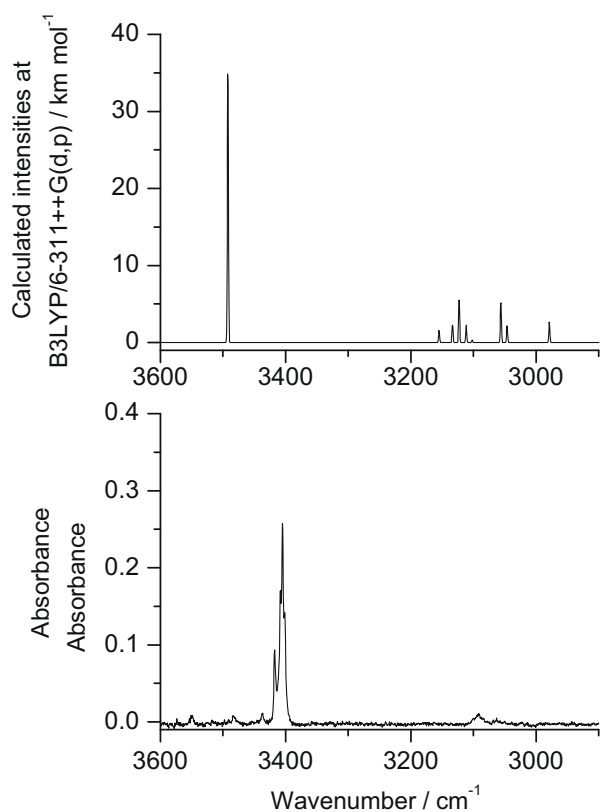

B
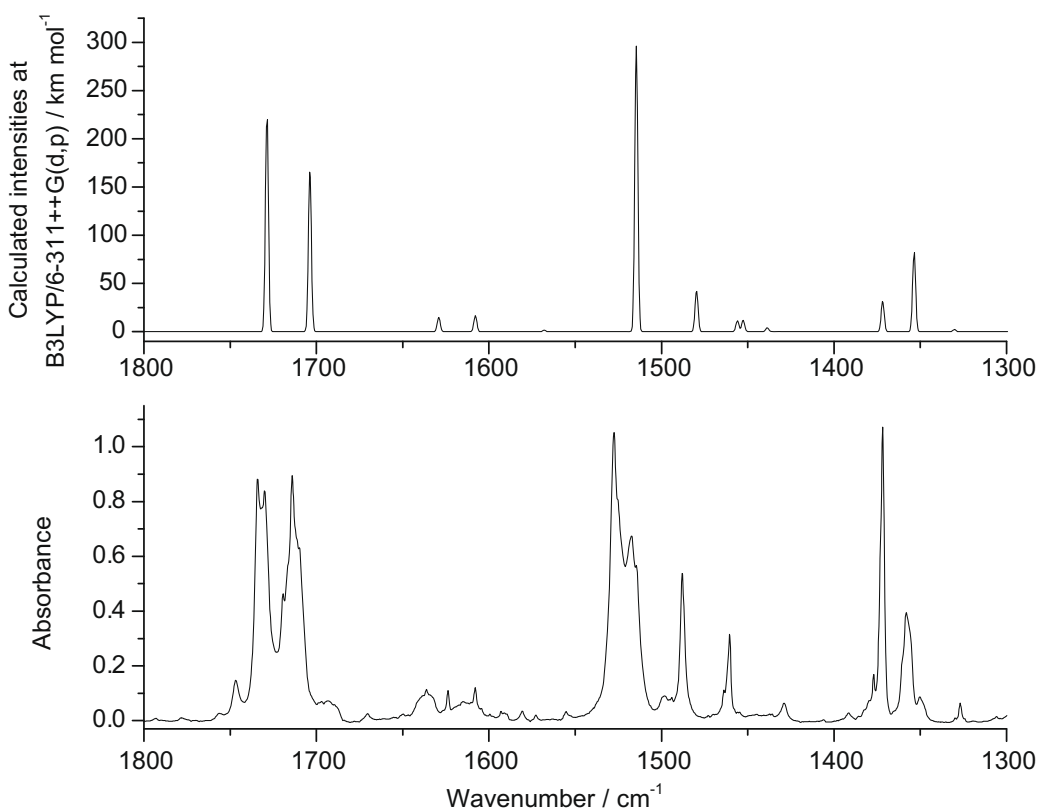

C
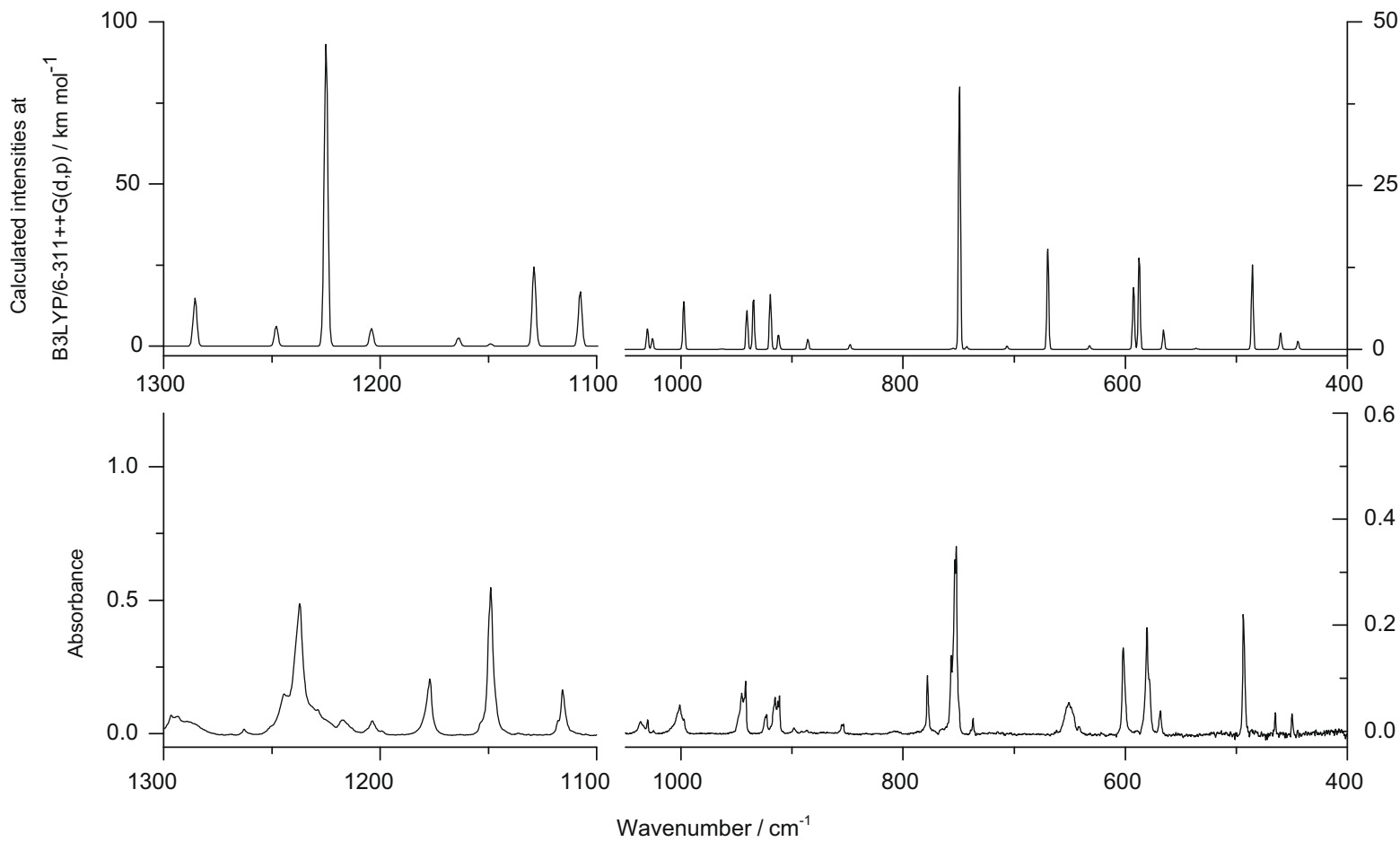

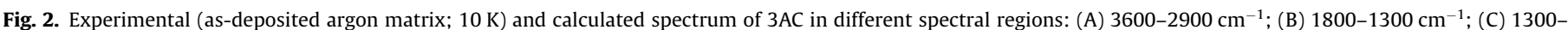

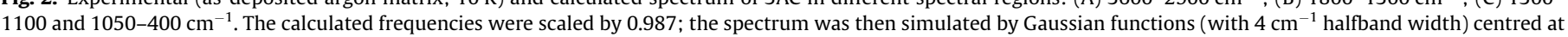
the calculated scaled frequencies.

Note that the assignment of the $778 \mathrm{~cm}^{-1}$ experimental band to the $\gamma \mathrm{N}-\mathrm{H}$ rocking mode was also facilitated by the fact that no other band is predicted by the calculations to occur at this frequency (see Fig. 2).

\subsection{Photochemical experiments}

As mentioned in Section 1, the $\alpha$-pyrone moiety has been shown to exhibit an interesting photochemistry [9-14], with both the ring-opening (to isomeric ketene) and ring-contracting (to Dewar isomer) reactions being generally observed and their relative importance being influenced by the substituents present in the heterocyclic ring. An interesting point was the observation that the presence of a volumous group at the position 3 of the $\alpha$-pyrone ring strongly reduces the importance of the ring-contraction reaction for the matrix-isolated compounds, in view of the energetically demanding reorganization of the matrix host atoms that would be required to accommodate the newly formed strongly 
Table 1

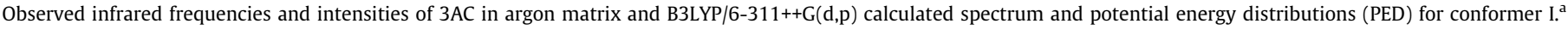

\begin{tabular}{|c|c|c|c|c|}
\hline \multicolumn{2}{|c|}{ Observed } & \multicolumn{2}{|c|}{ Calculated } & \multirow[t]{2}{*}{ PED $^{\text {d }}$} \\
\hline Freq. & Int. ${ }^{b}$ & Freq. $^{c}$ & Int. & \\
\hline \multirow{12}{*}{$\begin{array}{l}3417.9 \\
3408.3 \\
3405.3 \\
3401.6\end{array}$} & 106.9 & 3492.3 & 76.3 & $v(\mathrm{NH})(100)$ \\
\hline & & & & \\
\hline & & & & \\
\hline & & & & \\
\hline & & 3154.8 & 3.4 & $v(\mathrm{C} 4-\mathrm{H})(100)$ \\
\hline & & 3133.4 & 4.9 & $v(\mathrm{C} 7-\mathrm{H})(72)+v(\mathrm{C} 8-\mathrm{H})(21)$ \\
\hline & & 3122.9 & 11.8 & $v(\mathrm{C} 8-\mathrm{H})(57)+v(\mathrm{C} 4-\mathrm{H})(19)+v(\mathrm{C} 9-\mathrm{H})(15)$ \\
\hline & & 3111.5 & 4.8 & $v(\mathrm{C} 8-\mathrm{H})(54)+v(\mathrm{C} 10-\mathrm{H})(36)$ \\
\hline & & 3102.1 & 0.7 & $v(\mathrm{C} 10-\mathrm{H})(49)+v(\mathrm{C} 9-\mathrm{H})(34)+v(\mathrm{C} 8-\mathrm{H})(16)$ \\
\hline & & 3056.2 & 11.3 & $v\left(\mathrm{CH}_{3}\right)_{\text {as }}(90)+v\left(\mathrm{CH}_{3}\right)^{\prime}{ }_{\text {as }}(10)$ \\
\hline & & 3046.4 & 4.8 & $v\left(\mathrm{CH}_{3}\right)^{\prime}{ }_{\text {as }}(90)+v\left(\mathrm{CH}_{3}\right)_{\text {as }}(10)$ \\
\hline & & 2978.9 & 5.9 & $v\left(\mathrm{CH}_{3}\right)_{s}(100)$ \\
\hline 1733.8 & 381.9 & 1728.7 & 481.5 & $v(\mathrm{C} 2=0)(79)$ \\
\hline \multicolumn{5}{|l|}{1729.6} \\
\hline 1719.4 & 438.4 & 1703.8 & 361.9 & $v(\mathrm{C} 19=0)(76)$ \\
\hline \multicolumn{5}{|l|}{1713.9} \\
\hline \multicolumn{5}{|l|}{1709.7} \\
\hline 1636.7 & 36.7 & 1629.1 & 32.1 & $v(\mathrm{C} 3=\mathrm{C} 4)(51)$ \\
\hline 1607.7 & Overlap with $\mathrm{H}_{2} \mathrm{O}$ & 1607.9 & 35.6 & $v(\mathrm{C} 7-\mathrm{C} 6)(18)+v(\mathrm{C} 10=\mathrm{C} 9)(18)+v(\mathrm{C} 10-\mathrm{C} 5)(12)+v(\mathrm{C} 8=\mathrm{C} 7)(12)$ \\
\hline n.o. & & 1568.0 & 3.1 & $v(\mathrm{C} 5=\mathrm{C} 6)(18)+v(\mathrm{C} 9-\mathrm{C} 8)(18)+v(\mathrm{C} 8=\mathrm{C} 7)(14)+\delta(\mathrm{C} 8-\mathrm{H})(10)$ \\
\hline 1527.2 & 585.9 & 1514.6 & 635.0 & $\delta(\mathrm{NH})(50)+v(\mathrm{~N}-\mathrm{C} 19)(13)$ \\
\hline \multicolumn{5}{|l|}{1517.5} \\
\hline \multicolumn{5}{|l|}{1514.5} \\
\hline 1488.0 & 98.9 & 1479.7 & 91.4 & $\delta(\mathrm{C} 10-\mathrm{H})(16)+\delta(\mathrm{C} 7-\mathrm{H})(14)+v(\mathrm{C} 5=\mathrm{C} 6)(12)+\delta(\mathrm{C} 9-\mathrm{H})(11)$ \\
\hline 1463.8 & 17.4 & 1456.0 & 24.5 & $\delta\left(\mathrm{CH}_{3}\right)^{\prime}$ as $(50)+\delta\left(\mathrm{CH}_{3}\right)_{\text {as }}(25)$ \\
\hline 1460.8 & 30.8 & 1452.7 & 25.5 & $\delta(\mathrm{C} 8-\mathrm{H})(22)+\delta(\mathrm{C} 9-\mathrm{H})(17)+v(\mathrm{C} 10=\mathrm{C} 9)(11)+v(\mathrm{C} 7-\mathrm{C} 6)(11)$ \\
\hline 1428.8 & 14.8 & 1438.7 & 8.7 & $\delta\left(\mathrm{CH}_{3}\right)_{\text {as }}(59)+\delta\left(\mathrm{CH}_{3}\right)^{\prime}{ }_{\text {as }}(29)$ \\
\hline 1376.9 & 130.1 & 1353.6 & 175.7 & $\delta(\mathrm{C} 4-\mathrm{H})(24)+v(\mathrm{C} 4-\mathrm{C} 5)(14)$ \\
\hline \multicolumn{5}{|l|}{1372.1} \\
\hline 1358.2 & 164.2 & 1371.7 & 68.4 & $\delta\left(\mathrm{CH}_{3}\right)_{s}(86)$ \\
\hline 1350.4 & & & & \\
\hline 1326.8 & 7.6 & 1330.2 & 4.9 & $v(\mathrm{C} 10=\mathrm{C} 9)(19)+v(\mathrm{C} 8=\mathrm{C} 7)(17)+v(\mathrm{C} 5=\mathrm{C} 6)(17)+v(\mathrm{C} 9-\mathrm{C} 8)(10)$ \\
\hline 1296.1 & 36.1 & 1285.5 & 31.4 & $\delta(\mathrm{C} 7-\mathrm{H})(15)+\delta(\mathrm{C} 10-\mathrm{H})(12)+\delta(\mathrm{C} 8-\mathrm{H})(10)+v(\mathrm{C} 2-\mathrm{C} 3)(10)$ \\
\hline 1262.8 & 2.9 & 1248.0 & 13.1 & $v(\mathrm{C} 4-\mathrm{C} 5)(20)+\delta(\mathrm{C} 7-\mathrm{H})(15)+v(\mathrm{C} 7-\mathrm{C} 6)(12)+\delta$ ring $2(11)$ \\
\hline 1244.7 & 173.4 & 1224.9 & 198.1 & $v(\mathrm{~N}-\mathrm{C} 19)(26)+\delta(\mathrm{NH})(17)$ \\
\hline 1236.8 & & & & \\
\hline 1228.4 & & & & \\
\hline 1177.1 & 37.8 & 1204.0 & 11.6 & $v(\mathrm{C} 6-\mathrm{O} 1)(26)+v(\mathrm{C} 10-\mathrm{C} 5)(14)+\delta(\mathrm{C} 4-\mathrm{H})(11)$ \\
\hline 1203.6 & 8.8 & 1163.8 & 5.4 & $\delta(\mathrm{C} 4-\mathrm{H})(27)+\delta(\mathrm{C} 10-\mathrm{H})(12)+v(\mathrm{C} 3-\mathrm{N})(12)$ \\
\hline n.o. & & 1149.0 & 1.6 & $\delta(\mathrm{C} 9-\mathrm{H})(27)+\delta(\mathrm{C} 8-\mathrm{H})(16)$ \\
\hline 1148.7 & 90.5 & 1128.9 & 52.2 & $v(\mathrm{O} 1-\mathrm{C} 2)(33)$ \\
\hline 1117.9 & 26.1 & 1107.6 & 35.8 & $v(\mathrm{C} 8=\mathrm{C} 7)(14)+\delta(\mathrm{C} 8-\mathrm{H})(13)+v(\mathrm{C} 10=\mathrm{C} 9)(13)+v(01-\mathrm{C} 2)(12)$ \\
\hline 1115.6 & & & & \\
\hline 1036.5 & 7.0 & 1030.2 & 6.8 & $\gamma\left(\mathrm{CH}_{3}\right)_{\text {as }}(72)+\gamma(\mathrm{C} 19-\mathrm{O} 20)(19)$ \\
\hline 1030.0 & 1.0 & 1025.7 & 3.6 & $v(\mathrm{C} 9-\mathrm{C} 8)(43)+v(\mathrm{C} 8=\mathrm{C} 7)(14)+\delta(\mathrm{C} 7-\mathrm{H})(13)+v(\mathrm{C} 10=\mathrm{C} 9)(12)$ \\
\hline 997.2 & 14.0 & 997.5 & 15.6 & $\gamma\left(\mathrm{CH}_{3}\right)_{s}(50)+v(\mathrm{C} 21-\mathrm{C} 19)(16)$ \\
\hline n.o. & & 963.3 & 0.1 & $\gamma(\mathrm{C} 9-\mathrm{H})(51)+\gamma(\mathrm{C} 8-\mathrm{H})(42)+\gamma(\mathrm{C} 10-\mathrm{H})(20)+\gamma(\mathrm{C} 7-\mathrm{H})(10)$ \\
\hline 945.3 & 10.3 & 940.5 & 12.7 & $\gamma(\mathrm{C} 10-\mathrm{H})(33)+\gamma(\mathrm{C} 7-\mathrm{H})(30)+\gamma(\mathrm{C} 8-\mathrm{H})(23)+\gamma(\mathrm{C} 4-\mathrm{H})(18)$ \\
\hline 941.8 & 14.0 & 934.7 & 16.4 & $v(\mathrm{~N}-\mathrm{C} 19)(26)+\gamma\left(\mathrm{CH}_{3}\right)_{s}(12)+\delta$ ring $2(10)+v(\mathrm{C} 6-\mathrm{C} 7)(10)$ \\
\hline 915.2 & 16.8 & 919.6 & 17.8 & $\gamma(\mathrm{C} 4-\mathrm{H})(86)$ \\
\hline 912.7 & & & & \\
\hline 911.5 & & & & \\
\hline 923.2 & 4.1 & 912.2 & 4.7 & $\delta$ ring $2(35)+\delta$ ring $1(13)$ \\
\hline 898.5 & 2.1 & 885.8 & 3.3 & $v(\mathrm{C} 21-\mathrm{C} 19)(15)+\delta \operatorname{ring} 2(13)+v(01-\mathrm{C} 2)(11)$ \\
\hline 854.2 & 1.6 & 847.6 & 1.6 & $\gamma(\mathrm{C} 7-\mathrm{H})(44)+\gamma(\mathrm{C} 10-\mathrm{H})(35)+\gamma(\mathrm{C} 9-\mathrm{H})(10)$ \\
\hline n.o. & & 754.9 & 0.3 & $\gamma(\mathrm{C} 2=0)(68)+\gamma(\mathrm{C} 3-\mathrm{N})(21)$ \\
\hline 756.7 & 69.2 & 749.1 & 87.7 & $\gamma(\mathrm{C} 9-\mathrm{H})(29)+\gamma(\mathrm{C} 8-\mathrm{H})(26)+\gamma(\mathrm{C} 10-\mathrm{H})(14)+\gamma(\mathrm{C} 7-\mathrm{H})(12)$ \\
\hline 753.6 & & & & \\
\hline 752.1 & & & & \\
\hline n.o. & & 742.7 & 0.9 & $v(\mathrm{C} 5=\mathrm{C} 6)(19)+\delta \operatorname{ring} 2^{\prime}(13)+v(\mathrm{C} 21-\mathrm{C} 19)(11)$ \\
\hline n.o. & & 709.8 & 0.02 & $\tau$ ring $2(88)+\tau$ ring $1(14)$ \\
\hline n.o. & & 706.4 & 1.0 & $\delta$ ring $1(32)+\delta$ ring $2^{\prime \prime}(15)$ \\
\hline 778.0 & 11.3 & 669.6 & 33.5 & $\gamma(\mathrm{NH})(79)+\gamma(\mathrm{C} 19=\mathrm{O})(18)$ \\
\hline 651.1 & Overlap with $\mathrm{CO}_{2}$ & 632.1 & 1.2 & $\delta$ ring $2^{\prime}(28)+\delta(C 2=0)(23)+\delta$ ring $1(10)$ \\
\hline 601.6 & 22.2 & 592.5 & 20.0 & $\delta$ ring $1^{\prime}(23)+\delta(\mathrm{C} 19=0)(16)+v(\mathrm{C} 2-\mathrm{C} 3)(14)+\delta$ ring $2^{\prime}(10)$ \\
\hline 580.3 & 32.6 & 587.5 & 29.8 & $\gamma(\mathrm{C} 19=0)(58)+\gamma(\mathrm{NH})(27)+\tau\left(\mathrm{CH}_{3}\right)(13)$ \\
\hline 578.1 & & & & \\
\hline 568.5 & 5.5 & 565.5 & 6.3 & $\delta$ ring $2^{\prime \prime}(25)+\delta$ ring $2^{\prime}(22)+\delta(\mathrm{C} 2=0)(14)$ \\
\hline n.o. & 0.0 & 536.3 & 0.3 & $\tau$ ring $2^{\prime \prime}(52)+\tau \operatorname{ring} 1(26)+\tau$ ring $2(22)$ \\
\hline 493.7 & 24.2 & 485.4 & 27.4 & $\delta(\mathrm{C} 19=0)(30)+\delta$ ring $1^{\prime \prime}(20)+\delta(\mathrm{C} 21-\mathrm{C} 19-\mathrm{N})(15)+\delta$ ring $1^{\prime}(10)$ \\
\hline 464.7 & 1.8 & 460.1 & 5.3 & $\tau$ ring $2^{\prime}(54)+\tau$ Butterfly $(35)$ \\
\hline 449.7 & 1.6 & 444.5 & 2.6 & $\delta$ ring $1^{\prime}(26)+\delta$ ring $1^{\prime \prime}(23)+v(\mathrm{C} 6-01)(12)+\delta$ ring $2^{\prime}(11)$ \\
\hline
\end{tabular}

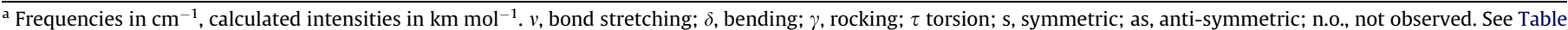
S1 for definition of symmetry coordinates.

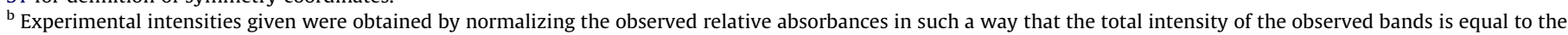
total intensity of the calculated bands having an experimental counterpart.

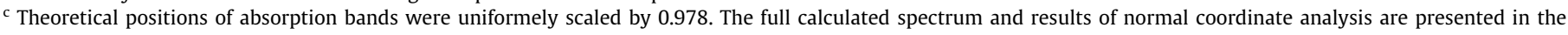
Supplementary data Table S3.

d PED's lower than $10 \%$ are not included. 
non-planar Dewar species $[13,14]$. Since $3 A C$ is a molecule bearing a relatively volumous substituent at the position 3 of the $\alpha$-pyrone ring, the photochemical ring-contraction reaction could be expected not to take place easily for the matrix-isolated compound. Another interesting a priori question related with the possibility or not of $3 \mathrm{AC}$ also undergo decarbonylation reaction in a similar way to what was observed for coumarin [21]. Furthermore, there was also the question of the photochemical stability of the amide moiety under the present experimental conditions. Lundell et al. [37] reported the first photolysis experiments of formamide in both argon and xenon matrices through irradiation with an excimer laser operating at $193 \mathrm{~nm}(\mathrm{ArF})$, and observed two major channels, leading to the formation of $\mathrm{CO}$ and $\mathrm{HNCO}$, complexed with $\mathrm{NH}_{3}$ and $\mathrm{H}_{2}$, respectively. The vacuum UV photolysis $(\lambda>160 \mathrm{~nm})$ of acetamide was also studied at low temperature (in argon matrix) by Duvernay et al. [38], which found $\mathrm{HNCO}: \mathrm{CH}_{4}$ and $\mathrm{CO}: \mathrm{CH}_{3} \mathrm{NH}_{2}$ molecular complexes as main products, together with acetimidic acid.

The irradiation experiments performed in the present study used a similar approach to that used in our previous study of coumarin [21]. In particular, different cut-off filters were used: $\lambda>337$, $315,285,235 \mathrm{~nm}$ and, finally, unfiltered radiation $(\lambda>215 \mathrm{~nm})$. No changes in the spectra were observed upon irradiation with the filtered light. On the other hand, unfiltered irradiation led to appearance of new bands growing in the $2150-2125 \mathrm{~cm}^{-1}$ region. Fig. 3 shows the $2200-1650 \mathrm{~cm}^{-1}$ range of the spectra of the as-deposited and irradiated $(\lambda>215 \mathrm{~nm} ; 215 \mathrm{~min}$.) matrix of 3AC, showing the appearance of the bands due to photoproducts and consumption of the bands of the reactant. This figure also presents data we previously obtained for unsubstituted coumarin subjected to identical irradiation experiments, for comparison.

The first conclusion that can be extracted from this figure is that, as found for coumarin, upon photolysis with $\lambda>215 \mathrm{~nm}$ matrix-isolated 3AC undergoes a ring-opening Norrish type I $\alpha$-cleavage to its isomeric ketene. Indeed, the band observed in the spectra of the irradiated matrix at $2138 \mathrm{~cm}^{-1}$ can be assigned to the $v \mathrm{C}=\mathrm{C}=\mathrm{O}$ anti-symmetric stretching mode of the ketene in a geometry with the $(\mathrm{O}=) \mathrm{C}-\mathrm{C}=\mathrm{C}-\mathrm{C}(=\mathrm{C}=\mathrm{O})$ fragment in the E conformation. This is exactly the frequency for the same vibration observed in the spectra of the irradiated matrix of coumarin, whose assignment has been discussed in detail in Ref. [21]. Very interestingly, the band at $2120 \mathrm{~cm}^{-1}$ observed in the spectra of the irradiated matrix of coumarin (see Fig. 3 ) and assigned to the $\mathrm{Z}$ isomers of the ketene [21], has no equivalent in the case of 3AC, as it could be expected taking into account that all the low energy $\left(\Delta E<49 \mathrm{~kJ} \mathrm{~mol}^{-1}\right)$ conformers of the $3 A C$ ketene have an $\mathrm{E}$ arrangement of the $(\mathrm{O}=) \mathrm{C}-\mathrm{C}=\mathrm{C}-\mathrm{C}(=\mathrm{C}=\mathrm{O})$ fragment, because in the $\mathrm{Z}$ forms a strong steric repulsion between the acetamido-ketene substituent and the carbonyl group of the ketene ring exists (see Fig. 4, where the geometries and relative energies of the most stable forms of the 3AC ketene isomer are shown).

The second observation is that $\mathrm{CO}$ is also produced in the photolysis of 3AC. In fact, like for coumarin, we can expect decarbonylation reaction to take place in $3 \mathrm{AC}$, to give rise to the corresponding substituted benzofuran. In addition, once produced the benzofuran shall form a complex with the extruded $\mathrm{CO}$ in the matrix cage initially occupied by the reactant molecule. In this complex, the relative orientation of the CO molecule with respect to benzofuran may be different and the shoulders observed at 2146 and $2142 \mathrm{~cm}^{-1}$ (Fig. 3) are with all probability due to these species. Indeed, these shoulders appear at the same positions of the small bands previously [21] assigned to the benzofuran/CO complexes obtained from photolysis of matrix-isolated coumarin (see Fig. 3). Very unfortunately, the benzofuran moiety does not give rise to any strong or medium intensity characteristic infrared band that can be clearly visible in the spectra of the irradiated
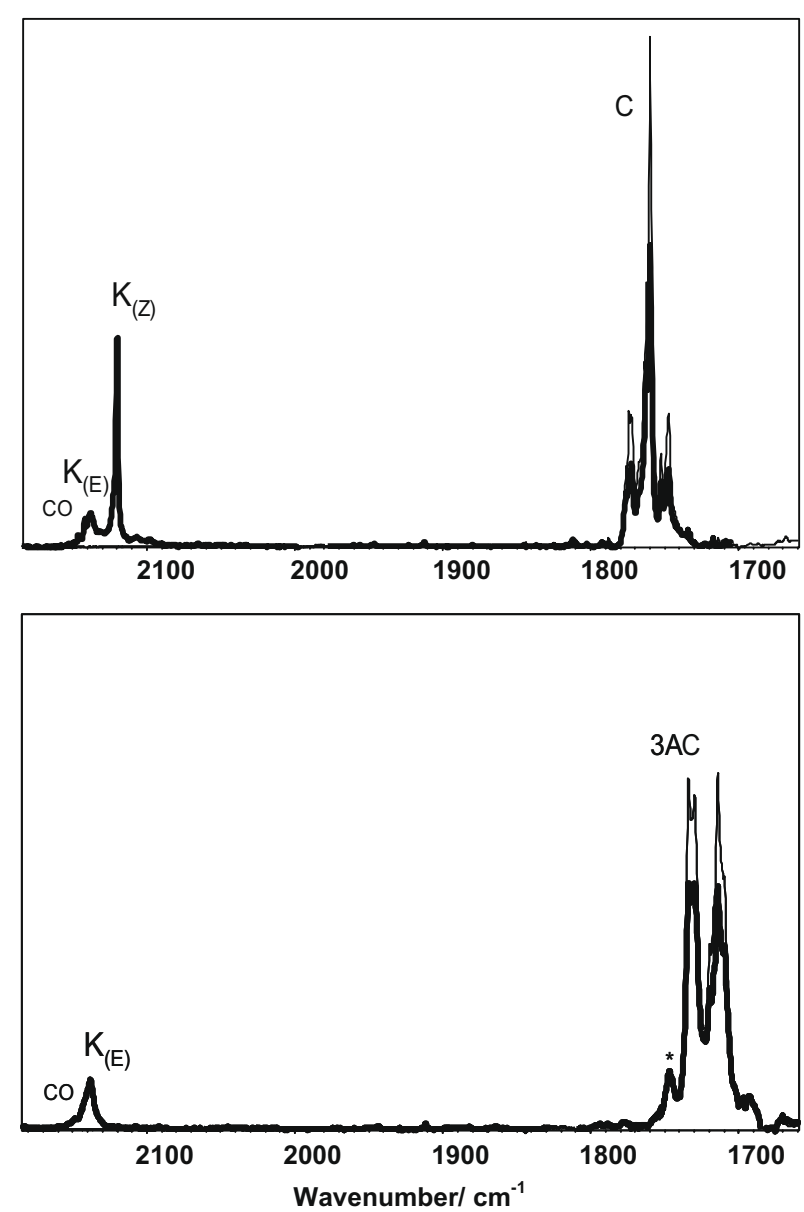

Fig. 3. $2200-1650 \mathrm{~cm}^{-1}$ spectral region of the spectra of $3 \mathrm{AC}$ (bottom) and coumarin (C; top) before (thin lines) and after (bold lines) UV irradiation $(\lambda>215 \mathrm{~nm})$. For 3AC total time of irradiation was $215 \mathrm{~min}$.; for coumarin, $90 \mathrm{~min}$. The band marked with asterisk in the spectra of $3 \mathrm{AC}$ is due to an unknown trace impurity. $\mathrm{K}_{(\mathrm{Z})}$ and $\mathrm{K}_{(\mathrm{E})}$ indicate bands due to ketene forms with the $(\mathrm{O}=) \mathrm{C}-\mathrm{C}=\mathrm{C}-\mathrm{C}(=\mathrm{C}=\mathrm{O})$ fragment in the $\mathrm{Z}$ and $\mathrm{E}$ conformation, respectively.
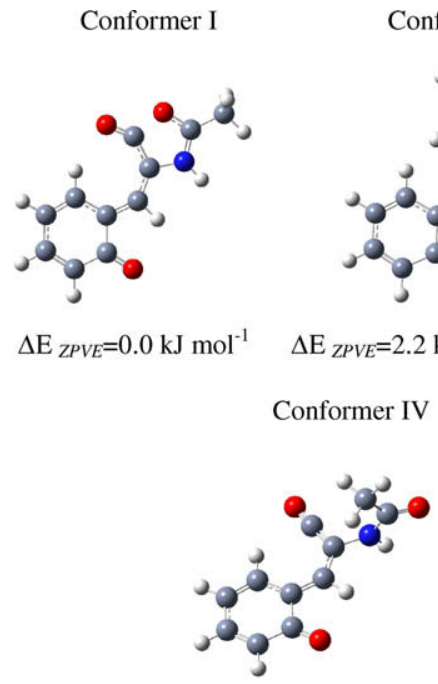

$\Delta \mathrm{E}_{Z P V E}=37.3 \mathrm{~kJ} \mathrm{~mol}^{-1}$

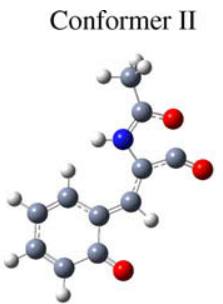

j

$=2.2 \mathrm{~kJ} \mathrm{~mol}^{-1}$
$\Delta \mathrm{E}_{Z P V E}=32.2 \mathrm{~kJ} \mathrm{~mol}^{-1}$

\section{Conformer V}

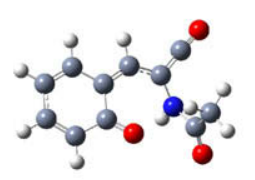

$$
\Delta \mathrm{E}_{Z P V E}=49.0 \mathrm{~kJ} \mathrm{~mol}^{-1}
$$

Fig. 4. Lowest energy conformers of the isomeric ketene of $3 \mathrm{AC}$, calculated at the B3LYP/6-311++G(d,p) level of theory. Forms I to IV have their $(\mathrm{O}=) \mathrm{C}-\mathrm{C}=\mathrm{C}-\mathrm{C}(=\mathrm{C}=\mathrm{O})$ fragment in the $\mathrm{E}$ conformation, while conformer $\mathrm{V}$ corresponds to the lowest energy conformer of the ketene possessing the $\mathrm{Z}$ arrangement of the $(\mathrm{O}=) \mathrm{C}-\mathrm{C}=\mathrm{C}-\mathrm{C}(=\mathrm{C}=\mathrm{O})$ fragment. 
matrix at the level of concentration resulting from the photoinduced reaction. Such observation would certainly strenghtened the conclusion regarding occurrence of the decarbonylation photoprocess. Note that, on the other hand, the band centered at $2138 \mathrm{~cm}^{-1}$ cannot be attributed to $\mathrm{CO}$, even if a minor contribution of this species to the total intensity of the band cannot be excluded, since the carbon monoxide absorption is weak in infrared and, if all area below the absorption band at $2138 \mathrm{~cm}^{-1}$ would originate in $\mathrm{CO}$, this would require the amount of photoproduced $\mathrm{CO}$ molecules to be more than three times the amount of consumed 3AC. On the other hand, the ketene moiety gives rise to an extremely strong infrared absorption (above $1000 \mathrm{~km} \mathrm{~mol}^{-1}$ ) in this region.

The third conclusion that can be extracted from Fig. 3 is related with the relative facility of the two compounds (3AC and coumarin) to react under the experimental conditions used. For coumarin, it was observed a decrease in the band intensities indicating that $38 \%$ of the initially present compound has already been consumed, while only $21 \%$ of $3 A C$ was transformed after 215 min. irradiation. There are two main justifications for the smaller ability of $3 A C$ to react: (i) Firstly, the number of opened reaction photochannels is different in $3 \mathrm{AC}$ and coumarin. In coumarin, besides the ring-opening reaction to the ketene form and the decarbonylation reaction, isomerization to the Dewar form was also observed, which after decarboxylation led to the final observed product, a bicyclo[4.2.0]octa-1,3,5,7-tetraene $/ \mathrm{CO}_{2}$ complex [21]. On the other hand, there are no indications in the spectra of the irradiated matrix of $3 \mathrm{AC}$ of production of these species, a result that is also in agreement with the fact that when the $\alpha$-pyrone moiety has a volumous substituent at the position 3, the ring-contraction photoreaction leading to the Dewar form is strongly unfavoured in low temperature matrix $[13,14]$. (ii) Secondly, the ring-opening reaction process can also be expected to be intrinsically less favored in $3 A C$ than in coumarin, due to the presence in the first molecule of the amido substituent. As stated in Section 1 conjugative type substitution in the $\alpha$-pyrone ring, blue-shifts the $S_{1} \leftarrow S_{0}\left(n \pi^{*}\right)$ transition and red-shifts the $S_{2} \leftarrow S_{0}\left(\pi \pi^{*}\right)$ transition $[17,18]$, reducing the gap between the $S_{1}$ and $S_{2}$ states and disfavoring the process leading to the ketene formation relatively to that leading to isomerization to the Dewar form. So, in 3AC the ketene formation channel can be expected to be less efficient, whereas by the reasons already pointed out the channel leading to the Dewar form is not active for the matrix-isolated reactant. In addition, there has been noticed that the transition states for decarbonylation and ketene formation for coumarin [21] are located very closely on the potential energy surface which may imply the existence of an efficient "cross-road" between the isomerization and decarbonylation photochannels. It can be expected that a similar situation occurs for $3 \mathrm{AC}$, which could then also be a factor contributing to the smaller reactivity found for $3 \mathrm{AC}$ when compared to coumarin.

\section{Conclusions}

In this study, the infrared spectrum of $3 A C$ isolated in solid argon was recorded and assigned. Theoretical calculations predicted the existence of three different conformers of $3 \mathrm{AC}$. However, in consonance with the theoretically estimated relative energies of the conformers, only the most stable form was observed experimentally. This conformer is stabilized by two intramolecular $\mathrm{H}$ bonds and similar to the structural unit found in crystalline $3 \mathrm{AC}$ [30]. UV $(\lambda>215 \mathrm{~nm})$ irradiation of the matrix-isolated compound was found to lead to isomerization of the compound to its openring isomeric ketene. In consonance with the theoretical structural predictions for the most stable isomers of this photoproduct, the experimental data indicated that it is produced in the $\mathrm{E}$ arrangement of the $(\mathrm{O}=) \mathrm{C}-\mathrm{C}=\mathrm{C}-\mathrm{C}(=\mathrm{C}=\mathrm{O})$ fragment. There were also experimental indications pointing to occurrence of photochemical decarbonylation of $3 \mathrm{AC}$, leading to formation of a benzofuran/CO complex. On the other hand, no photochemical production of Dewar isomer of $3 \mathrm{AC}$ was observed, contrarily to what is generally observed for $\alpha$-pyrones derivatives, including unsubstituted coumarin. This later result, came in the line of the results obtained for the methyl coumalates $[13,14]$, and reinforced the idea that the isomerization of matrix-isolated $\alpha$-pyrones bearing relatively volumous substituents at the position 3 to the corresponding Dewar form is a disfavored process. This can be interpreted as being a consequence of the unfavorable relaxation of the matrix around the guest molecule that in these cases isomerization to the Dewar form implies, in view of the strong deviation from the planarity of these later species that then strongly mismatch the primarily occupied matrix sites. The relative ability of $3 \mathrm{AC}$ and coumarin were also compared and an explanation proposed for the smaller reactivity found for $3 \mathrm{AC}$ under the used experimental conditions.

\section{Acknowledgement}

S. Breda thanks the Portuguese Science Foundation (Fundação para a Ciência e a Tecnologia (FCT, Portugal) for the Grant \#SFRH/BD/16119/2004. Preliminary studies on 3AC were done under the projects POCI/QUI/58937/2004 (FCT, Portugal) and \#200519010 (Eskişehir Osmangazi University, Turkey) and the European Union Erasmus Programme.

\section{Appendix A. Supplementary data}

Supplementary data associated with this article can be found, in the online version, at doi:10.1016/j.molstruc.2008.10.013.

\section{References}

[1] A. Burger, Burger's Medicinal Chemistry, in: M.E. Wolf (Ed.), WileyInterscience, New York, 1995.

[2] I.E.M. Bultink, W.F. Lems, P.J. Kostense, B.A.C. Dijkmans, A.E. Voskuyl, Arthritis Rheum. 52 (2005) 2044.

[3] R.A. O’Reilly, J. Clinic. Investig. 46 (1967) 829.

[4] H. Zhao, N. Neamati, H. Hong, A. Mazumder, S. Wang, S. Sunder, G.W.A. Milne, Y. Pommier, T.R. Burke, J. Med. Chem. 40 (1997) 242.

[5] J. Hirsh, J.E. Dalen, D.R. Anderson, L. Poller, H. Bussey, J. Ansell, D. Deykin, Chest 119 (2001) 8S.

[6] Y. Kashman, K.R. Gustafson, R.W. Fuller, J.H. Cardellina, J.B. McMahon, M.J. Currens, R.W. Buckheit, S.H. Hughes, G.M. Cragg, M.R. Boyd, J. Med. Chem. 35 (1992) 2735

[7] K.C. Fylaktakidou, D.J. Hadjipavlou-Litina, K.E. Litinas, D.N. Nicolaides, Curr. Pharm. Design 10 (2004) 3813.

[8] R.N. Gacche, D.S. Gond, N.A. Dhole, B.S. Dawane, J. Enz. Inhib. Med. Chem. 21 (2006) 157

[9] S. Breda, L. Lapinski, R. Fausto, M.J. Nowak, Phys. Chem. Chem. Phys. 5 (2003) 4527.

[10] S. Breda, L. Lapinski, I. Reva, R. Fausto, J. Photochem. Photobiol. A 162 (2004) 139.

[11] S. Breda, I. Reva, L. Lapinski, R. Fausto, Phys. Chem. Chem. Phys. 6 (2004) 929.

[12] S. Breda, I.D. Reva, L. Lapinski, L. Frija, M.L. Cristiano, R. Fausto, J. Phys. Chem. A 110 (2006) 6415

[13] I.D. Reva, M.J. Nowak, L. Lapinski, R. Fausto, Chem. Phys. Lett. 429 (2006) 382.

[14] I.D. Reva, M.J. Nowak, L. Lapinski, R. Fausto, Chem. Phys. Lett. 452 (2008) 20.

[15] N.J. Turro, Modern Molecular Photochemistry, University Science Books, Sausalito, California, USA, 1991

[16] M. Klessinger, J. Michl, Excited States and Photochemistry of Organic Molecules, VCH, New York, USA, 1995.

[17] J.S. Seixas de Melo, G. Quinteiro, J. Pina, S. Breda, R. Fausto, J. Mol. Struct. 565/ 566 (2001) 59

[18] R.S. Becker, Theory and Interpretation of Fluorescence and Phosphorescence, Wiley/Interscience, New York, USA, 1969

[19] E.W.G. Diau, C. Kotting, A.H. Zewail, ChemPhysChem 2 (2001) 273.

[20] E.W.G. Diau, C. Kotting, A.H. Zewail, ChemPhysChem 2 (2001) 294.

[21] N. Kuş, S. Breda, I. Reva, E. Tasal, C. Ogretir, R. Fausto, Photochem. Photobiol. 83 (2007) 1237. Erratum: Photochem. Photobiol. 83 (2007) 1541.

[22] T. Yatsuhashi, N. Nakashima, J. Phys. Chem. A 104 (2000) 1095

[23] A.D. Becke, Phys. Rev. A 38 (1988) 3098.

[24] C.T. Lee, W.T. Yang, R.G. Parr, Phys. Rev. B 37 (1988) 785 
[25] M.J. Frisch, G.W. Trucks, H. B. Schlegel, G.E. Scuseria, M.A. Robb, J.R. Cheeseman, J.A. Montgomery, Jr., T. Vreven, K.N. Kudin, J.C. Burant, J.M. Millam, S.S. Iyengar, J. Tomasi, V. Barone, B. Mennucci, M. Cossi, G. Scalmani, N. Rega, G.A. Petersson, H. Nakatsuji, M. Hada, M. Ehara, K. Toyota, R. Fukuda, J. Hasegawa, M. Ishida, T. Nakajima, Y. Honda, O. Kitao, H. Nakai, M. Klene, X. Li, J. E. Knox, H.P. Hratchian, J.B. Cross, V. Bakken, C. Adamo, J. Jaramillo, R. Gomperts, R.E. Stratmann, O. Yazyev, A.J. Austin, R. Cammi, C. Pomelli, J.W. Ochterski, P.Y. Ayala, K. Morokuma, G.A. Voth, P. Salvador, J.J. Dannenberg, V.G. Zakrzewski, S. Dapprich, A.D. Daniels, M.C. Strain, O. Farkas, D.K. Malick, A.D. Rabuck, K. Raghavachari, J.B. Foresman, J.V. Ortiz, Q. Cui, A.G. Baboul, S. Clifford, J. Cioslowski, B.B. Stefanov, G. Liu, A. Liashenko, P. Piskorz, I. Komaromi, R.L. Martin, D.J. Fox, T. Keith, M.A. Al-Laham, C.Y. Peng, A. Nanayakkara, M. Challacombe, P.M. W. Gill, B. Johnson, W. Chen, M.W. Wong, C. Gonzalez, J.A. Pople, Gaussian 03, Revision C.02, Gaussian, Inc., Wallingford CT, 2004.

[26] J.H. Schachtschneider, Technical Report, Shell Development Co., Emeryville, CA, 1969.

[27] P. Pulay, G. Fogarasi, F. Pang, J.E. Boggs, J. Am. Chem. Soc. 101 (1979) 2550.

[28] G. Keresztury, G. Jalsovszky, J. Mol. Struct. 10 (1971) 304.
[29] F.J. Martínez-Martínez, I.I. Padilla-Martínez, J. Trujillo-Ferrara, Magn. Reson. Chem. 39 (2001) 765.

[30] E.V. García-Baez, F.J. Mariınez-Martínez, H. Hopfl, I.I. Padilla-Martínez, Crysta Growth \& Design 3 (2003) 35.

[31] A. Sharma, I.D. Reva, R. Fausto, J. Phys. Chem. A 112 (2008) 5935.

[32] S. Breda, I.D. Reva, L. Lapinski, M.J. Nowak, R. Fausto, J. Mol. Struct. 786 (2006) 193

[33] R. Fausto, I. D. Reva, A. Gómez-Zavaglia, in: T.M.V.D. Pinho e Melo, A.M.d:A Rocha Gonsalves (Eds.), Recent Research Developments in Heterocyclic Chemistry , 37/661 (2), Fort P.O., Trivandrum-695 023, Kerala, India, 2007.

34] M. Rozenberg, G. Shoham, I.D. Reva, R. Fausto, Spectrochim. Acta A 62 (2005) 233.

[35] M. Rozenberg, G. Shoham, I.D. Reva, R. Fausto, Phys. Chem. Chem. Phys. 7 (2005) 2376.

[36] M. Rozenberg, G. Shoham, I.D. Reva, R. Fausto, Spectrochim. Acta A 60 (2004) 463.

[37] J. Lundell, M. Krajewska, M. Räsänen, J. Phys. Chem. A 102 (1998) 6643.

[38] F. Duvernay, P. Chatron-Michaud, F. Borget, D.M. Birney, T. Chiavassa, Phys. Chem. Chem. Phys. 9 (2007) 1099. 